\title{
ОБЗОР ОСНОВНЫХ ТЕОРЕТИЧЕСКИХ ПОДХОДОВ \\ И ЭМПИРИЧЕСКИХ ИССЛЕДОВАНИЙ \\ ЭФФЕКТИВНОСТИ СДЕЛОК СЛИЯНИЙ И ПОГЛОЩЕНИЙ
}

Родионов И.И.1, Михальчук В.Б.2

Компании развивающихся рынков, таких как Китай, Индия, Малайзия, Россия и ЮАР, активно используют слияния и поглощения как важный инструмент развития и выхода на глобальные рынки. После кризиса 2008 года в сделках между компаниями с развитых и развивающихся рынков более четверти от общей суммы сделок были инициированы компаниями с развивающихся рынков.

Для компаний развивающихся рынков сделки слияний и поглощений выступают одним из важнейших элементов программы долгосрочного развития. Эмпирические исследования последних лет показывают, что мотивы и способы достижения синергии компаниями с развитых и развивающихся рынков отличаются.

Компании США и Европы, как правило, выходят на рынок слияний и поглощений для получения экономии на масштабе. На рынках с низкими темпами роста снижение расходов для увеличения рентабельности является наиболее надежным путем к увеличению прибыли. Компании с развивающихся рынков в сделках слияний и поглощений стремятся прежде всего к приобретению недостающих компетенций - технологий, брендов, бизнес-моделей - или талантливого персонала, а также к облегчению выхода на фондовые рынки развитых стран.

В связи с этим существует необходимость уточнения, определения и анализа факторов, влияющих на создание синергии сделок слияний и поглощений на развивающихся рынках.

Целью статьи является систематизация существующего опыта анализа и оценки синергии для теоретического обоснования модели, подходящей для оценки размера синергии и эмпирической проверки гипотез о значимости факторов создания синергии в сделках слияний и поглощений в России.

В статье проведен обзор основных теоретических работ, посвященных анализу синергии в сделках слияний и поглощений, определены основные факторы создания синергии и методы оценки синергии на развивающихся рынках. Проанализированы различия в факторах создания стоимости в сделках слияний и поглощений на развитых и развивающихся рынках.

Ключевые слова: слияния и поглощения, синергия, стоимость компании, развивающиеся рынки капитала

JEL: G30, G34

\section{Понятие и виды синергии в сделках слияния и поглощения}

Под синергией в случае сделок слияния и поглощения принято понимать дополнительную стоимость, созданную в результате объединения двух компаний, открывшего для объединенной компании новые возможности, недоступные компаниям по отдельности и повысившего ее конкурентоспособность. В литературе разделяют два основных вида синергии: операционную и финансовую.

Операционная синергия позволяет компаниям увеличить операционную прибыль от существующих активов, ускорить темпы роста или и то и другое одновременно. Операционная синергия обычно проявляются в возросших денежных потоках и разделяются на четыре основных вида:

1. Экономия на масштабе позволяет сократить издержки компании, делая ее более прибыльной. Создание экономии на масштабе предполагается в горизонтальных сделках - слияниях и поглощениях в рамках одного бизнеса.

1. Д-р эконом. наук, проф. кафедры экономики и финансов фирмы факультета экономики НИУ ВШЭ, г. Москва.

2. Аспирант кафедры экономики и финансов фирмы факультета экономики НИУ ВШЭ, г. Москва. 
2. Усиление рыночной позиции возникает из-за снижения конкуренции и увеличения доли рынка, что приводит к росту маржинальности и операционной прибыли. Эта синергия также проявляется в сделках между фирмами, работающими в том же самом бизнесе.

3. Сочетание различных функциональных компетенций возникает, когда компания с сильными компетенциями в маркетинге приобретает компанию с широкой продуктовой линейкой и т.п.

4. Ускорение темпа роста за счет слияний и поглощений может происходить, когда компания на стабильном развитом рынке покупает компанию с быстрорастущего развивающегося рынка.

Финансовая синергия включает налоговые преимущества, диверсификацию и более высокую емкость доступного долга, а также новые инвестиционные возможности для свободной наличности. Финансовая синергия может проявляться в форме возросших денежных потоков или снижения ставки дисконтирования и WACC. Финансовые синергии разделяются также на четыре основных вида.

1. Налоговые выгоды у объединенной компании возникают, когда в процессе слияния используются налоговые законы для увеличения стоимости активов поглощаемой компании, или для зачета накопленных убытков к снижению будущих налогов на прибыль.

2. Диверсификация может создать финансовую синергию для неторгуемых компаний или на низколиквидных рынках, когда инвесторы не могут диверсифицировать свои вложения самостоятельно. Однако для публичных компаний на развитых рынках диверсификация со стороны инвесторов, как правило, обходится дешевле, чем диверсификация со стороны компаний за счет слияний и поглощений.

3. Емкость доступного долга увеличивается, если будущие потоки денежных средств компании становятся более стабильными и предсказуемыми. Этот вид финансовой синергии проявляется в снижении WACC объединенной компании.

4. Реализация прибыльных инвестиционных проектов становится возможной, когда компания с большим объемом свободных денежных средств и отсутствием перспективных проектов покупает компанию с хорошими возможностями для инвестирования и ограниченной наличностью. Синергия возникает также от реализации прибыльных проектов, которые компании не могли бы реализовать поодиночке.

\section{Факторы создания синергии на развитых и развивающихся рынках}

Существует обширная литература на тему того, как и при каких условиях сделки слияний и поглощений создают синергию. Большинство исследований посвящено развитым рынкам, в особенности США, как наиболее крупному рынку слияний и поглощений.

В последние 10-15 лет развиваются исследования сделок между компаниями развивающихся рынков с такими же компаниями и компаниями с развитых рынков. В основном они посвящены компаниям Восточной Европы, Азии и Латинской Америки. Исследовательский интерес к проблеме эффективности слияний и поглощений на российском рынке, а также российских компаний на развитых рынках в последние годы вырос вместе со смещением активности по приобретению компаний в сторону развивающихся рынков.

Можно выделить следующие основные направления исследований последних лет, наиболее близкие к рассматриваемой проблеме:

1. Исследования создания синергии в сделках слияния и поглощения между компаниями развивающегося и развитого рынка (Aybar and Ficici, 2009), различных развивающихся рынков (Ма, 2012), развитого и развивающегося рынков (Aw, 2000; Eckbo, 2000; Moeller et al., 2004; Francis et al., 2008; Liao and Williams, 2008; Chari et al., 2010; Geluebcke and John, 2012; Damijan et al., 2012; Goddard et al., 2012) и различных развитых рынков (Andrande et al., 2001; Moeller et al., 2005). 
2. Изучение влияния характеристик участвующих компаний и самой сделки на создание синергии (Чиркова и Чувствинина, 2011; Аглиарди и Лукьянова, 2011; Rani et al., 2012; Григорьева и Троицкий, 2012; Григорьева и Гринченко, 2013). К характеристикам компаний относятся такие факторы, как отрасль, размер, опыт, публичность, концентрация собственности, долговая нагрузка и другие. Сделки характеризуются такими факторами, как вид оплаты, вид слияния, премия, дружественность и другие.

3. Изучение влияния различных стратегий корпоративного управления на создание синергии после завершения сделки (Cartwright, 1993; Ulrich et al., 2005; Bartles, 2006; Dick, 2006).

4. Изучение особенностей создания синергии в сделках слияния и поглощения в рамках так называемой долевой экономики ${ }^{1}$. Быстрые темпs роста лидирующих компаний в долевой экономике делает их привлекательными целями для поглощений со стороны крупных компаний в смежных традиционных отраслях ${ }^{2}$. Эти проблемы исследовались во многих работах (Bardhi and Eckhardt, 2012: Zervas et al.,2014; May and Horney, 2014; Horney, 2015).

Среди основных факторов создания синергии в сделках слияния и поглощения на развитых и развивающихся рынках исследуются следующие факторы (таблица 1):

Таблица 1

\section{Основные факторы создания синергии}

\begin{tabular}{|c|c|c|}
\hline Фактор создания синергии & $\begin{array}{c}\text { Эффект на создание } \\
\text { синергий на развитых } \\
\text { рынках }\end{array}$ & $\begin{array}{c}\text { Эффект на создание } \\
\text { синергий на } \\
\text { развивающихся рынках }\end{array}$ \\
\hline \multicolumn{3}{|l|}{ Вид оплаты: } \\
\hline - оплата акциями & Смешанный & Позитивный \\
\hline - оплата наличными & Позитивный & Позитивный \\
\hline \multicolumn{3}{|l|}{ Вид слияния: } \\
\hline - горизонтальные & Позитивный & Позитивный \\
\hline - вертикальные & Незначим & Позитивный \\
\hline Размер компаний & Негативный & Негативный \\
\hline Размер сделки & Смешанный & Негативный \\
\hline Общая отрасль & Позитивный & Не изучался \\
\hline Премия & Негативный & Не изучался \\
\hline Выбор времени & $\begin{array}{c}\text { Во время повышенной } \\
\text { активности сделок M\&A } \\
\text { синергия ниже }\end{array}$ & Не изучался \\
\hline $\begin{array}{c}\text { Качество менеджмента } \\
\text { персонала }\end{array}$ & Позитивный & Не изучался \\
\hline $\begin{array}{c}\text { Сохранение предыдущего } \\
\text { топ-менеджмента }\end{array}$ & Позитивный & Не изучался \\
\hline
\end{tabular}

1. Долевая экономика, или совместное потребление (sharing economy, access-based consumption), - это экономика, в которой потребление благ происходит без передачи прав собственности, а сделки заключаются онлайн на платформе посредника. К наиболее крупным отраслям долевой экономики относятся аренда личной недвижимости, коллективное использование частного автотранспорта и оборудования, наем внештатных сотрудников, децентрализованное кредитование и финансирование (Р2P lending, crowdfunding), потоковая передача данных (streaming).

2. Так, в 2013 г. одна из крупнейших компаний по прокату автомобилей, Avis, объявила о покупке сервиса по коллективному пользованию частным автотранспортом Zipcar за 491 млн долл., предложив 50\%-ную премию к цене акций. В 2015 г. компания Нуatt, управляющая сетями отелей высшего класса, приобрела Onefinestay сервис аренды частных элитных квартир и домов. 


\begin{tabular}{|c|c|c|}
\hline Опыт & Позитивный & Смешанный \\
\hline $\begin{array}{c}\text { Доля государственной } \\
\text { собственности в капитале } \\
\text { целевой компании }\end{array}$ & Незначим & Позитивный \\
\hline $\begin{array}{c}\text { Публичность целевой } \\
\text { компании }\end{array}$ & Смешанный & Смешанный \\
\hline $\begin{array}{c}\text { Степень концентрации } \\
\text { собственности в } \\
\text { компаниях-покупателях }\end{array}$ & Не изучался & Смешанный \\
\hline $\begin{array}{c}\text { Уровень долговой } \\
\text { нагрузки }\end{array}$ & Зависит от отрасли & Зависит от отрасли \\
\hline $\begin{array}{c}\text { Приобретаемая доля в } \\
\text { компании }\end{array}$ & Незначим & Позитивный \\
\hline Дружественность сделки & Позитивный & Позитивный \\
\hline Степень интеграции & Не изучался & Негативный \\
\hline
\end{tabular}

Единое мнение о характере значимости многих факторов еще не сложилось. Исследования сделок M\&A на развивающихся рынках показывают, что значимость фактора часто зависит от особенностей конкретной страны, что делает исследования рынка слияний и поглощений в России интересными и актуальными.

Представляется, что проведенный анализ основных факторов создания синергии указывает на наличие трех перспективных направлений для будущих исследований:

1. Изучение значимости неисследованных факторов создания синергии в сделках на развивающихся рынках, в частности, таких, как премия, общая отрасль, сохранение предыдущего топ-менеджмента и выбор времени для проведения сделки.

2. Изучение причин существования различий в факторах создания синергии на развитых и развивающихся рынках. В частности, к таким факторам относятся вид оплаты, размер сделки, вид слияния, приобретаемая доля в компании, доля государственной собственности в капитале целевой компании.

3. Углубление анализа сделок M\&A до уровня отдельных развивающихся стран для выявления факторов создания синергии, особенных для этой страны.

\section{Методы оценки операционной синергии}

Операционная синергия может быть оценена методом дисконтирования денежных потоков как разница между стоимостью новой компании и суммарной стоимостью компаний до сделки слияния и поглощения.

Алгоритм оценки синергии методом дисконтирования денежных потоков включает три этапа:

- Оценка стоимости двух компаний по отдельности, при этом дисконтируются ожидаемые денежные потоки по средневзвешенной стоимости капитала для каждой компании.

- Оценка стоимости объединенной компании без учета синергии как суммы текущих стоимостей компаний, полученных на предыдущем этапе.

- Оценка стоимости объединенной компании с учетом синергии, одновременно закладываются новые темпы роста и денежные потоки. Разница между стоимостью объединенной компании с учетом синергии и стоимостями отдельных компаний равна стоимости синергии.

В академической литературе для оценки общей операционной синергии обычно используется показатель избыточной доходности за определенный промежуток времени (Agrawal et al., 1992; Markides, 1998). Под избыточной доходностью понимается разница между доход- 
ностью от инвестиций в акции компании, участвующей в сделке M\&A, и доходностью рыночного индекса за тот же период времени. Предполагается, что изменение капитализации компании после объявления о сделке на эффективном рынке отразит текущую стоимость синергии.

Оценка операционной синергии методом накопленной избыточной доходности имеет несколько недостатков для анализа сделок на развивающихся рынках. Хотя данные по фондовому рынку доступны, на развивающихся рынках лишь небольшая доля компаний торгуется. Даже в этом случае низкая ликвидность торгов не всегда позволяет выявить справедливую стоимость акции только на основании рыночных котировок (Tuch and O’Sullivan, 2007). Также этот метод не подходит для анализа небольших слияний, поскольку акции участвующих в сделке компаний обычно не торгуются на бирже.

Имеющиеся исследования позволяют оценить два отдельных компонента операционной синергии:

- Для оценки экономии на масштабе в предыдущих исследованиях использовались показатели эффективности и производительности компаний после сделки. Например, в работе Хейли и соавторов (Healy, 1992) компании в выборке после слияния показали улучшение в оборачиваемости активов и экономию на капитальных расходах на $25 \%$.

- Оценка усиления рыночной позиции проводится посредством сравнения цен на основные продукты участвующих в сделке компаний до и после сделки. Например, Ким и Сингал (Kim and Singal, 1993) обнаружили, что слияние авиаперевозчиков приводит к значительному увеличению цен на перевозки после сделки.

\section{Методы оценки финансовой синергии}

Общая финансовая синергия обычно оценивается на основании показателей отчетности (Kusewitt, 1985; Ramaswamy, 1997) или на основании оценки изменения ставки дисконтирования после сделки (Godfrey and Espinosa, 1996; Lessard, 1996).

Среди показателей отчетности используются такие показатели рентабельности, как рентабельность активов, отношение EBITDA к выручке и некоторые другие. Базой для сравнения могут быть финансовые показатели до и после сделки для той же компании или сравнение с динамикой среднего показателя по индустрии.

Анализ литературы показывает, что представляется возможным оценить три отдельных компонента финансовой синергии:

1. Для компаний с избыточной наличностью и отсутствием проектов существует мотивация приобрести компанию с наличием инвестиционных проектов и недостатком свободной наличности. Прирост стоимости в результате синергии в такой ситуации равен текущей стоимости всех инвестиционных проектов, которые будут реализованы в результате сделки поглощения. Этот компонент финансовой синергии объясняется улучшением доступности финансирования для поглощаемой компании или эффективной реализацией избыточной наличности для поглощающей компании.

2. Одна из компаний имеет накопленные налоговые вычеты, которые она не может использовать из-за убытков в текущем периоде. Другая компания в то же время выплачивает значительные налоги. Объединение двух таких компаний ведет к экономии на налогах, которые могут быть использованы обеими компаниями. Другая возможность экономии на налогах заключается в возможности увеличить амортизацию за счет активов поглощаемой компании. Синергия в таких сделках равна текущей стоимости экономии на налогах, возникшей в результате слияния (Hayn, 1989). Этот компонент финансовой синергии объясняется экономией на налогах.

3. Для оценки увеличения емкости доступного долга и, как следствие, снижения стоимости капитала, можно построить зависимость между долей долга (прокси - кредитный рейтинг компании) и WACC. Компания может значительно снизить WACC, если 
ей удастся улучшить свой кредитный рейтинг. Финансовой синергией в этом случае будет дополнительная стоимость компании, возникшая в результате снижения ставки дисконтирования.

Исследования выявили вклад каждого из компонентов финансовой синергии в зависимости от улучшения кредитного рейтинга компании (табл. 2).

Таблица 2

Компоненты финансовой синергии (\% от стоимости компаний, рассматриваемых поотдельности)

\begin{tabular}{|c|c|c|c|}
\hline Вид финансовой синергии & $\begin{array}{c}\text { Улучшение рейтинга с А } \\
\text { до АА }\end{array}$ & $\begin{array}{c}\text { Улучшение рейтинга с ВВВ } \\
\text { до А }\end{array}$ & $\begin{array}{c}\text { Улучшение рейтинга с BВ до } \\
\text { BBB }\end{array}$ \\
\hline Снижение стоимости капитала & $(2 \%)$ & $1-2 \%$ & $7-8 \%$ \\
\hline Экономия на налогах & $0 \%$ & $0-1 \%$ & $1 \%$ \\
\hline $\begin{array}{c}\text { Улучшение доступности финан- } \\
\text { сирования }\end{array}$ & $7-8 \%$ & $4 \%$ & $5 \%$ \\
\hline Общая финансовая синергия & $5-6 \%$ & $5-7 \%$ & $13-14 \%$ \\
\hline
\end{tabular}

Источник: Morgan, J.P. A shifting landscape for synergies, 2009.

В литературе отмечается, что операционная и финансовая синергии могут быть оценены с помощью интервью с топ-менеджерами. Этот метод заключается в опросе ключевых участников о результатах сделки и причинах успеха или неудачи. В исследованиях синергии для более чем 20 сделок такой метод был впервые применен Китчингом в 1967 году (Kitching, 1967). Позднее данный подход активно применялся в работах, связанных с исследованиями динамики сочетания корпоративной культуры и организационной структуры после слияний и поглощений.

Подобное исследование синергии может быть искажено в сторону завышения положительности результатов, поскольку менеджеры раскрывают прогнозируемый размер синергии, только когда она положительна. Кроме того, прогнозы менеджмента могут быть излишне оптимистичными, если они включают не связанные со сделкой инициативы по повышению эффективности компании (например, сокращение расходов за счет оптимизации численности персонала) в расчет синергии от сделки.

Наконец, прогнозы менеджмента обычно не включают разбивку синергии по компонентам, а кроме того, величина синергии обычно не разбита по годам. Это затрудняет анализ операционной и финансовой составляющих синергии.

В большинстве исследований развивающихся рынков операционная и финансовая синергия не разделяется, что представляется неоправданным. В работах, посвященных изучению одного из видов синергии, как правило, не выделяются отдельные ее компоненты, что также, на наш взгляд, было бы полезным.

Используя комплексный расчет операционной и финансовой синергии сделок слияний и поглощений на основании рассмотренных методов, можно получить более полную оценку возникающих синергий по сравнению с традиционными методами. Кроме того, можно получить представление о структуре операционной и финансовой синергии и их доле в общей синергии сделки.

\section{Особенности оценки синергии на развивающихся рынках}

На развивающихся рынках часто возникает необходимость оценки синергии в сделках между неторгуемыми компаниями, доля которых в общем числе сделок М\&А является основной. В этом случае популярный в академической литературе метод оценки через избыточную доходность неприменим, и для расчета синергии приходится использовать метод дисконтирования денежных потоков.

Одной из важных проблем в оценке компаний на развивающемся рынке этим методом является расчет WACC с учетом дополнительных рисков, таких как страновые, риски ликвидности, 
информационные риски, а также недостаточная эффективность фондового рынка. Поэтому необходимо рассмотреть и оценить применимость нескольких распространенных методов учета этих рисков в оценке компаний с развивающихся рынков, которые могут быть использованы для более точного расчета синергии.

\section{Спреды на рынке государственных облигащий}

Широко распространенный метод учета дополнительного странового риска заключается в расчете спредов доходностей государственных облигаций с одинаковым сроком до погашения на развитом рынке (обычно США) и развивающемся рынке. Эти доходности отражают ожидания инвесторов о минимальном риске инвестиций в экономику, а разница между доходностями - специфический страновой риск. Эта премия учитывается при расчете ставки дисконтирования для оценки компании (как правило, в модели САРМ).

Несмотря на простоту этого метода, методологические проблемы возникают, если на развивающемся рынке не имеется облигаций, номинированных в долларах США или евро, облигаций с сопоставимым сроком до погашения. Использование облигаций с различным сроком до погашения приведет к недооценке долгосрочных проектов, поскольку кривая доходностей, как правило, растет с увеличением срока.

\section{Международный CAPM (G-CAPM) и местный CAPM (L-CAPM)}

Модель G-CAPM основывается на допущениях, что все международные финансовые рынки полностью интегрированы, у инвесторов во всех странах одинаковое отношение к риску, инвесторы могут перемещать капитал из одной страны в другую быстро, без ограничений и с минимальными транзакционными издержками.

Модель L-CAPM предполагает, что развивающиеся рынки отличаются от развитых рынков, инвесторы не могут перемещать капитал из одной страны в другую, инвестиции подвержены специфическим страновым рискам.

Модель G-САРM: $R_{\theta}=R_{f, G}+\beta_{G} \times\left(R_{m, G}-R_{f, G}\right)$

Модель L-CAРM: $R_{e}=R_{f, L}+R_{C}+\beta_{L} \times\left(R_{m, L}-R_{f, L}\right)$

$\left(R_{m, G}-R_{f, G}\right)_{-}$средняя рыночная премия на глобальном рынке; $\left(R_{m, L}-R_{f, L}\right)_{-}$рыночная премия на местном рынке.

$\beta_{G}$ - бета компании с глобальным рыночным индексом (например, Morgan Stanley Capital Markets World Index);

$\beta_{L}$ - бета компании на местном рынке.

$R_{f, G}$ - средняя безрисковая ставка;

$R_{f, L}$ - безрисковая ставка на местном рынке.

$R_{c}$ - спред доходностей сопоставимых государственных облигаций.

$R_{\varepsilon}$ - ставка дисконтирования на рынке.

Модель Лессарда

Лессард (Lessard, 1996) предложил использовать доходности американского рынка в качестве образца и корректировать их с учетом особенностей местного рынка: $R_{e}=R_{f, U S}+\beta_{L, U S} \times \beta_{U S} \times\left(R_{m, U S}-R_{f, U S}\right)$,

где:

$R_{f, U S}$ - безрисковая доходность на рынке США; 
$R_{m, \text { Us }}$ - рыночная доходность на рынке США;

$\beta_{L, U S}$ - бета доходности местного рынка и рынка США;

$\beta_{U S}$ - бета доходностей сопоставимых компаний или проектов на рынке США и доходности рынка США;

$R_{\varepsilon}$ - ставка дисконтирования на развивающемся рынке.

Модель Лессарда учитывает большинство рисков в ставке дисконтирования, однако модель в значительной степени зависит от допущения, что американский рынок является подходящим образцом. Бета доходности местного рынка и рынка США может значительно изменяться с течением времени, и найти сопоставимые компании или проекты для расчета $\beta_{U S}$ не всегда возможно.

\section{Модель Годфрея-Эспинозь}

Годфрей и Эспиноза (Godfrey and Espinosa, 1996) предлагают два новых фактора оценки ставки дисконтирования для развивающихся рынков. Авторы утверждают, что модель Лессарда может приводить к неправильным результатам. Например, рынки Венесуэлы, Аргентины, и Шри-Ланки отличаются отрицательной страновой бетой , и ставка дисконтирования для этих рынков оказывается ниже, чем ставка для рынка США. Годфрей и Эспиноза заменяют страновую бету в модели Лессарда на так называемую скорректированную бету, которая рассчитывается как отношение среднеквадратичного отклонения (СКО) доходностей развивающегося рынка к СКО доходностей развитого рынка.

Авторы предлагают использовать спреды на рынке государственных облигаций, но отмечают, что этот метод завышает ставку дисконтирования. Допускается, что скорректированная бета уже учитывает часть странового риска, поэтому суммирование всех компонентов приводит к двойному учету этих рисков. Годфрей и Эспиноза ссылаются на исследование Эрб и соавторов (Erb et al., 1995), в котором показано, что около 40\% волатильности акций объясняется экономическими и политическими факторами, уже учтенными в страновой премии.

Итоговая формула для расчета ставки дисконтирования по модели Годфрея-Эспинозы выглядит так:

$R_{e}=R_{f, U S}+R_{c}+\frac{\sigma_{L}}{\sigma_{U S}} \times\left(R_{m, U S}-R_{f, U S}\right) \times 0,6$,

где:

$R_{f, U s}$ - безрисковая доходность на рынке США;

$R_{m, U s}$ - рыночная доходность на рынке США;

$R_{c}$ - спред доходностей сопоставимых государственных облигаций;

$\sigma_{L}$ - СКО доходностей на развивающемся рынке;

$\sigma_{U S}$ - СКО доходностей на рынке США;

$R_{\varepsilon}$ - ставка дисконтирования на развивающемся рынке.

Недостатками этой модели являются довольно сильные допущения, которые были сделаны. Предполагается, что корреляция между всеми рынками равна 1 и что страновая премия за риск объясняет 40\% волатильности акций. Хотя это подтверждается средними данными по развивающимся рынкам, такие допущения могут быть неприменимы к некоторым конкретным странам.

Краткое сравнение рассмотренных выше моделей представлено в таблице 3. 
Сравнение моделей оценки ставки дисконтирования на развивающихся рынках

\begin{tabular}{|c|c|c|c|c|}
\hline Модель оценки & $\begin{array}{c}\text { Академическое } \\
\text { обоснование }\end{array}$ & $\begin{array}{c}\text { Способ корректи- } \\
\text { ровки ставки }\end{array}$ & $\begin{array}{c}\text { Простота приме- } \\
\text { нения }\end{array}$ & Когда используется \\
\hline $\begin{array}{c}\text { Спреды на рынке } \\
\text { государственных } \\
\text { облигаций }\end{array}$ & Нет & Кредитный риск & Просто & $\begin{array}{c}\text { Первоначальная оценка } \\
\text { дополнительного риска }\end{array}$ \\
\hline $\begin{array}{c}\text { Международный } \\
\text { САРМ }\end{array}$ & $\begin{array}{c}\text { Да, но } \\
\text { основан на } \\
\text { нереалистичных } \\
\text { допущениях }\end{array}$ & Глобальная бета & Просто & $\begin{array}{c}\text { На открытых и близких к развитым } \\
\text { рынках }\end{array}$ \\
\hline Местный САРМ & Да & $\begin{array}{c}\text { Местная бета и } \\
\text { кредитный риск }\end{array}$ & Просто & $\begin{array}{c}\text { У рынка должна быть хотя бы } \\
\text { низкая форма эффективности }\end{array}$ \\
\hline Модель Лессарда & Да & $\begin{array}{c}\text { Страновая бета к } \\
\text { рынку США }\end{array}$ & $\begin{array}{c}\text { Сложно найти } \\
\text { сопоставимые } \\
\text { проекты }\end{array}$ & $\begin{array}{c}\text { Если есть положительная } \\
\text { кореляция развивающегося рынка } \\
\text { с рынком США }\end{array}$ \\
\hline Модель Годфрея- \\
Эспинозы & $\begin{array}{c}\text { Основан на } \\
\text { нереалистичных } \\
\text { допущениях }\end{array}$ & $\begin{array}{c}\text { Относительная } \\
\text { волатильность и } \\
\text { кредитный риск }\end{array}$ & $\begin{array}{c}\text { Сложно найти } \\
\text { сопоставимые } \\
\text { проекты }\end{array}$ & $\begin{array}{c}\text { Если есть отрицательная } \\
\text { корреляция развивающегося рынка } \\
\text { с рынком США }\end{array}$ \\
\hline
\end{tabular}

В исследованиях, посвященных созданию синергии в сделках M\&A компаний развивающихся рынков, авторы часто ограничиваются рассмотрением сделок между публичными компаниями. Этот подход значительно ограничивает выборку из-за того, что одна или обе участвующие в сделке компании часто являются непубличными, и не дает полной картины. Представляется, что применение метода дисконтирования денежных потоков с учетом дополнительных рисков позволит оценить размер синергии в сделках между непубличными компаниями и увеличить выборку сделок для проведения регрессионного анализа значимости факторов создания синергии.

\section{Заключение}

Проведенный анализ подходов к оценке синергии показывает целесообразность применения комплексного метода оценки синергии в сделках M\&A на развивающихся рынках. Такой метод может включать оценку операционной синергии методом накопленной избыточной доходности и метода дисконтирования денежных потоков в сочетании с оценкой финансовой синергии на основании изменения рентабельности активов.

Представляется, что для российского рынка слияний и поглощений комплексный расчет операционной и финансовой синергии позволит получить более полную оценку возникающей синергии по сравнению с традиционными методами, особенно для компаний с неликвидными ценными бумагами и для сделок слияния небольших компаний. На российском рынке включение в анализ слияний и поглощений непубличных компаний позволит увеличить выборку с 58 до 810 сделок с объявленной стоимостью за период 2006-2015 гг. (табл. 4) и, следовательно, при использовании данных за ряд лет даст довольно полную картину значимости факторов синергии.

Таблиияа 4

Количество и общая объявленная стоимость сделок слияний и поглощений, инициированных российскими публичными и непубличными компаниями в России

\begin{tabular}{|c|c|c|c|c|}
\hline Год & $\begin{array}{c}\text { Количество } \\
\text { сделок, } \\
\text { инициированных } \\
\text { публичными } \\
\text { компаниями, ед. } \\
\text { инициированных } \\
\text { публичными } \\
\text { компаниями, млн } \\
\text { долл. }\end{array}$ & $\begin{array}{c}\text { Общая стоимость } \\
\text { сделок, } \\
\text { непубличными } \\
\text { компаниями, ед. } \\
\text { сделок, } \\
\text { компаниями, млн } \\
\text { долл. }\end{array}$ & $\begin{array}{c}\text { Общая стоимость } \\
\text { сделок, } \\
\text { инициированных }\end{array}$ \\
\hline 2006 & 2 & 637 & 110 & 13795 \\
\hline 2007 & 7 & 5826 & 150 & 39947 \\
\hline 2008 & 9 & 4737 & 109 & 37907 \\
\hline
\end{tabular}




\begin{tabular}{|c|c|c|c|c|}
\hline 2009 & 4 & 2822 & 47 & 9628 \\
\hline 2010 & 8 & 4524 & 63 & 22785 \\
\hline 2011 & 11 & 28499 & 85 & 29385 \\
\hline 2012 & 8 & 3761 & 69 & 26491 \\
\hline 2013 & 3 & 16262 & 82 & 67695 \\
\hline 2014 & 6 & 5468 & 74 & 30320 \\
\hline 2015 & 0 & 0 & 21 & 2528 \\
\hline Всего & 58 & 72536 & 810 & 280481 \\
\hline
\end{tabular}

По такой выборке на основании регрессионного анализа возможно не только определить наиболее значимые факторы создания синергии, но и выявить особенности создания синергии в сделках слияний и поглощений на российском рынке по сравнению с другими развивающимися рынками.

В частности, возможно протестировать следующие гипотезы для сделок слияний и поглощений, инициированных российскими компаниями в России:

Сделки во время кризиса 2013-2015 гг. привели к худшим результатам с точки зрения создания синергии по сравнению со сделками во время кризиса 2008-2009 гг.

Сделки 2010-2011 гг. не приводили к созданию синергии, в отличие от сделок в докризисный период, в 2006-2007 гг.

Факторы создания синергии в России в 2006-2007 гг. похожи на факторы создания синергии на развитых рынках.

Факторы создания синергии в России в 2010-2012 гг. похожи на факторы создания синергии на других развивающихся рынках.

\section{Список литературы}

1. Аглиарди Э., Лукьянова И. Финансовый рычаг, доходность и отраслевая специфика: эмпирическое исследование сделок слияний и поглощений // Корпоративные финансы. 2011. № 4(20). С. 54-76.

2. Григорьева С.А., Гринченко А.Ю. Влияние сделок слияний и поглощений в финансовом секторе на стоимость компаний-покупателей на развивающихся рынках капитала // Корпоративные финансы. 2013. № 4(28). С. 63-80.

3. Григорьева С.А., Троицкий П.В. Влияние слияний и поглощений на операционную эффективность компаний на развивающихся рынках капитала // Корпоративные финансы. 2012. № 3(23). С. 31-43.

4. Чиркова Е.В., Чувствина Е.В. Исследование факторов, влияющих на инвестиционную активность компании // Корпоративные финансы. 2011. № 3(19). С. 5-18.

5. Agrawal, A., Jaffe, J.F., and Mandelker, G.N. (1992), "The post-merger performance of acquiring firms: a re-examination of an anomaly", Journal of Finance, no. 47, pp. 16051621.

6. Andrade, G., Mitchell, M.L., and Stafford, E. (2001), "New evidence and perspectives on mergers", Journal of Economic Perspectives, vol. 15, no. 2, pp. 103-120

7. Aybar, B., and Ficici, A. (2009), "Cross-border acquisitions and firm value: an analysis of emerging-market multinationals", Journal of International Business Studies, no. 40, vol. $1317-1338$.

8. Bardhi, F., and Eckhardt, G.M. (2012), "Access-based consumption: the case of car sharing", Journal of Consumer Research, vol. 39, no. 4, pp. 881-898.

9. Bartels, J. (2006), “Organizational identification during a merger: determinants of employees' expected identification with the new organization”, British Journal of Management, no. 17. 
10. Cartwright, S. (1993), "The psychological impact of merger and acquisition on the individual: a study of building society managers", Human Relations, no. 46, pp. 327-347.

11. Chari, A., Ouimet, P.P., and Tesar, L.L. (2010), "The value of control in emerging markets", Review of Financial Studies, no. 23, pp. 1741-1770.

12. Damijan, J., Kostevc, C., and Rojec, M. (2012), “Growing lemons and cherries?”, Pre-and post-acquisition performance of foreign-acquired firms in new EU member states. Available at SSRN: http://ssrn.com/abstract=2279331.

13. Damodaran, A. (2005), "The value of synergy”. Available at SSRN 841486.

14. Dick, R. (2006), "Working under a black cloud: how to sustain organizational identification after a merger”, British Journal of Management, no. 17, p. S69.

15. Eckbo, B.E. (2000), "Gains to bidder firms revisited: Domestic and foreign acquisitions in Canada", Journal of Financial and Quantitative Analysis, vol. 35, no. 1.

16. Erb, C.B., Harvey, C.R., and Viskanta, T.E. (1996), "Expected returns and volatility in 135 countries". Available at SSRN 871253.

17. Francis, B.B., Hasan, I., and Sun, X. (2008), "Financial market integration and the value of global diversification: evidence for US acquirers in cross-border mergers and acquisitions", Journal of Banking \& Finance, no. 32, pp. 1522-1540.

18. Goddard, J., Molyneux, P., and Zhou, T. (2012), "Bank mergers and acquisitions in emerging markets: evidence from Asia and Latin America", The European Journal of Finance, vol. 18, no. 5, pp. 419-438.

19. Godfrey, S., and Espinosa, R. (1996), "A practical approach to calculating costs of equity for investments in emerging markets", Journal of Applied Corporate Finance, vol. 9, no. 3, pp. 80-90.

20. Hayn, C. (1989), "Tax attributes as determinants of shareholder gains in corporate acquisitions", Journal of Financial Economics, vol. 23, no. 1, pp. 121-153.

21. Healy, P., Palepu, K., and Ruback R. (1992), "Does corporate performance improve after mergers?”, Journal of Financial Economics, vol. 31, no. 2, pp. 135-175.

22. Horney, M. (2015), "Eight Takeaways from the FTC's", Sharing Economy Workshop Perspectives from FSF Scholars, vol. 10, no. 22.

23. Kim, E.H., and Singal, V. (1993), "Mergers and market power: Evidence from the airline industry", The American Economic Review, pp. 549-569.

24. Kitching, J. (1967), "Why do mergers miscarry", Harvard Business Review, vol. 45, no. 6, pp. 84-101.

25. Kusewitt, J.B. (1985), “An exploratory study of strategic acquisition factors relating to performance”, Strategic Management Journal, no. 6, pp. 151-169.

26. Lessard, D.R. (1996), "Incorporating country risk in the valuation of offshore projects", Journal of Applied Corporate Finance, vol. 9, no. 3, pp. 52-63.

27. Liao, A, and Williams, J. (2008), "Do win-win outcomes exist? A study of cross-border M\&A transactions in emerging markets", Comparative Economic Studies, no. 50, pp. 274-296.

28. Ma, J., Pagán, J.A., and Chu, Y. (2012), "Wealth effects of bank mergers and acquisitions in Asian emerging markets", The Journal of Applied Business Research, vol. 28, no. 1 pp. $47-58$.

29. Markides, C. (1998), "International acquisitions: do they create value for shareholders?", European Management Journal, no. 16, p.125.

30. May, R., and Horney, M. (2014), "The sharing economy: a positive shared", Vision for the Future Perspectives from FSF Scholars, vol. 9, no. 26.

31. Moeller, S.B., Schlingemann, F.P., and Stulz, R.M. (2004), "Firm size and the gains from 
acquisitions", Journal of Financial Economics, no. 73, pp. 201-228.

32. Moeller, S.B., Schlingemann, F.P., and Stulz, R.M. (2005), "Wealth destruction on a massive scale? A Study of Acquiring-Firm Returns in the Recent Merger Wave", Journal of Finance, no. 60 , pp. $757-782$.

33. Ramaswamy, K. (1997), "The performance Impact of strategic similarity in horizontal mergers: evidence from the US banking industry", Academy of Management Journal, no. 40, pp. 697-715.

34. Rani, N., Surendra, Y.S., and Jain, P.K. (2012), "Impact of mergers and acquisition on returns to shareholders of acquiring firms: Indian economy in perspective", Journal of Financial Management and Analysis, vol. 25, no. 1, pp. 1-24.

35. Tuch, C., and O'Sullivan, N. (2007), "The impact of acquisitions on firm performance: a review of the evidence", International Journal of Management Reviews, no. 9, pp. 141-170.

36. Ullrich, J., Wieseke, J., and Dick, R.V. (2005), "Continuity and change in mergers and acquisitions: a social identity case study of a German industrial merger", Journal of Management Studies, no. 42, pp. 1549-1569.

37. Zervas, G., Proserpio, D., and Byers, J. (2014), "The rise of the sharing economy: estimating the impact of Airbnb on the hotel industry". Boston U. School of Management Research Paper, no. 16. 


\title{
Rodionov Ivan, \\ Professor, department of economics and corporate finance National Research University Higher School of Economics, Moscow
}

Mikhalchuk Vitaly,

Postgraduate, department of economics and corporate finance National Research University Higher School of Economics, Moscow

\begin{abstract}
Companies from emerging markets, such as China, India, Malaysia, Russia and South Africa, use mergers and acquisitions (M\&A) as one of the main instruments to grow and enter global markets. After the global financial crisis in 2008, companies from emerging markets initiated over $25 \%$ of M\&A deals volume between developed and emerging markets companies.

M\&A decisions are vital for long-term development of emerging market companies. Recent empirical research shows that companies from developed and emerging markets have different motives and seek different types of synergy in M\&A deals.

Companies from United States and Europe usually look for economies of scale. On developed, low-growth markets one reliable way to higher profits is to reduce costs with economies of scale. Companies from emerging markets look for market competences that they are lacking: technologies, brands, business models or skilled employees. Therefore, there is a need to identify determinants of synergy creation in M\&A deals initiated by emerging markets companies.

This article aims to systematize existing literature about synergy and validate theoretical model suitable for synergy valuation and regression analysis of M\&A deal in Russia. We review academic research on M\&A synergy, identify major factors of synergy creation and methods of synergy valuation in emerging markets, analyze differences in major factors of synergy creation for developed and emerging markets.
\end{abstract}

Keywords: mergers and acquisitions, synergy, company valuation, emerging markets

JEL: G30, G34

\section{References}

1. Agliardi, E., Lukianova, I. 2011. Leverage, profitability, and industry specifics: empirical M\&A study. Journal of Corporate Finance [Agliardi E., Luk'janova I. Finansovyj rychag, dohodnost' i otraslevaja specifika: jempiricheskoe issledovanie sdelok slijanij i pogloshhenij // Korporativnye finansy. 2011 №4(20). S. 54-76.]

2. Grigorieva, S., Grinchenko, A. 2013. Impact of M\&A deals on company value in financial sector in emerging markets. Journal of Corporate Finance [Grigor'eva S.A., Grinchenko A. Vlijanie sdelok slijanij i pogloshhenij v finansovom sektore na stoimost' kompanijpokupatelej na razvivajushhihsja rynkah kapitala // Korporativnye finansy. 2013. №4(28). S. 63-80.]

3. Grigorieva, S., Troitsky, P. 2012. Impact of M\&A deals on operational efficiency in emerging markets. Journal of Corporate Finance [Grigor'eva S.A., Troickij P.V. Vlijanie slijanij i pogloshhenij na operacionnuju jeffektivnost' kompanij na razvivajushhihsja rynkah kapitala // Korporativnye finansy. 2012. №3(23). S. 31-43.]

4. Chirkova, E., Chuvstvina, E. 2011. Research of factors that influence company's investment activity. Journal of Corporate Finance [Chirkova E.V., Chuvstvina E.V. Issledovanie faktorov, vlijajushhih na investicionnuju aktivnost' kompanii // Korporativnye finansy. 2011. № 3(19). S. 5-18.Agrawal, A., Jaffe, J.F., Mandelker, G.N., 1992. The Post-Merger 